\title{
Ancient Thoughts and Electric Buildings
}

\section{Michael Trommer}

York University, Cinema and Media Arts

Keywords: Sonic Cartography, Acoustemology, Virtual Reality. Experimental Documentary

\section{Abstract:}

This paper discusses the 'Ancient Thoughts and Electric Buildings' project - an experimental, audio-led, virtual reality (VR) documentary that examines the portion of Toronto's downtown core that extends along the city's Gardner Expressway. This site traverses Canada's financial nexus and has been the recent locus of extensive condo and commercial development; simultaneously, it exists as a region that is (and has historically been) occupied by a significant number of homeless people.

This project seeks to foreground sound as a key sensory modality distinguishing the conditions of the locale's urban dispossessed from that of the privileged. To this end, spatial and haptic audio dissemination is deployed to emphasize the relentless cacophony within which the homeless remain perpetually exposed, a stark contrast to the acoustically sealed, climate-controlled, humming structures of the financial towers that their habitat is immersed in.

Visually, the documentary investigates the homeless population's reinterpretation of their imposed topography - beneath the cathedrals of commerce, highways become roofs and scrap material is reconfigured as walls and furniture in a surreal contemporary echo of feudal dynamics. Further emphasizing the socio-economic disconnect, fragments of local condominium marketing copy have been composited into the 360-degree space in order to highlight the disconcerting paradoxes inherent in the clash of these spatially overlapping, yet antithetical territories.

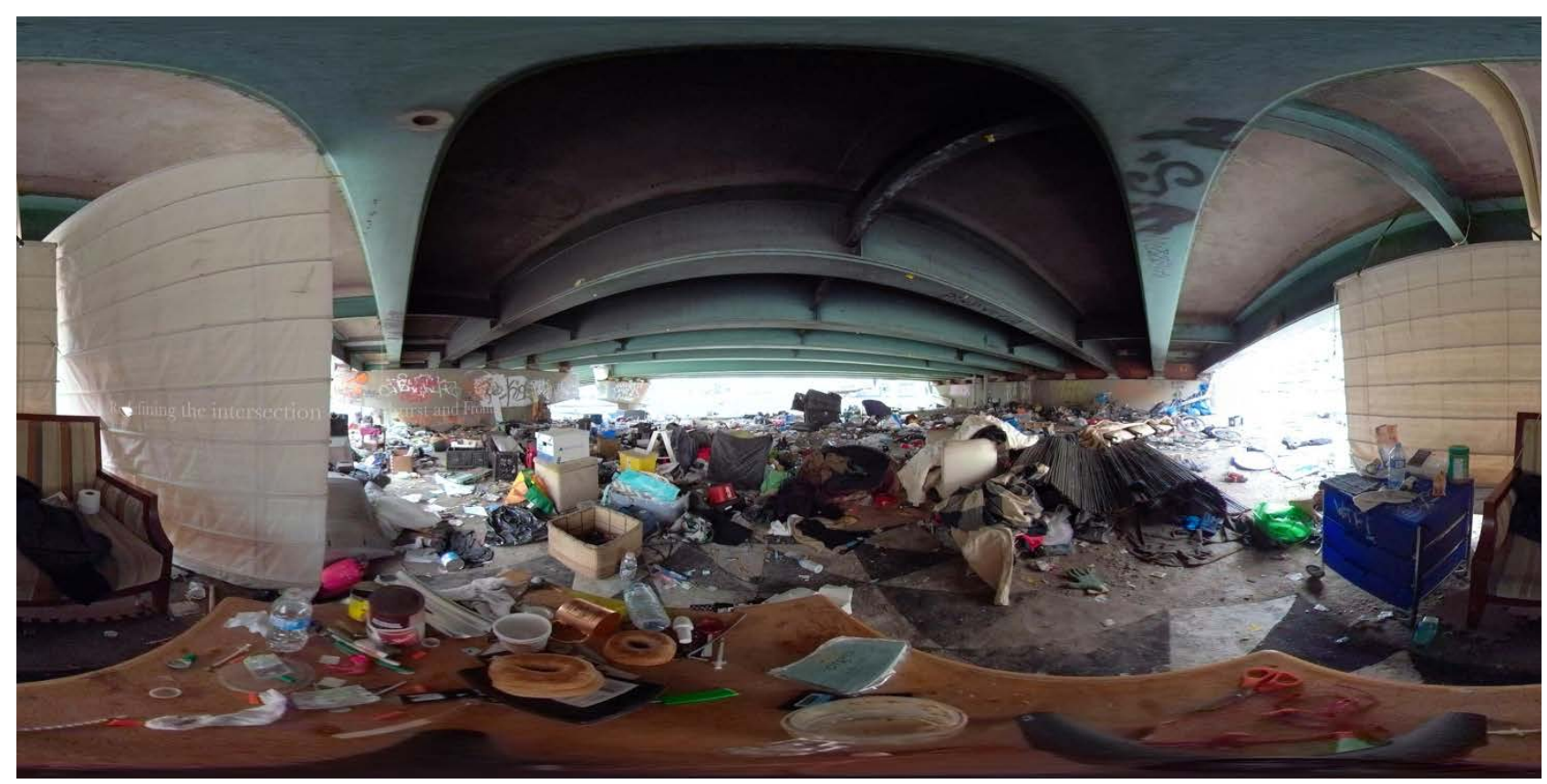

Figure 1. Ancient Thoughts and Electric Buildings: Production Still 


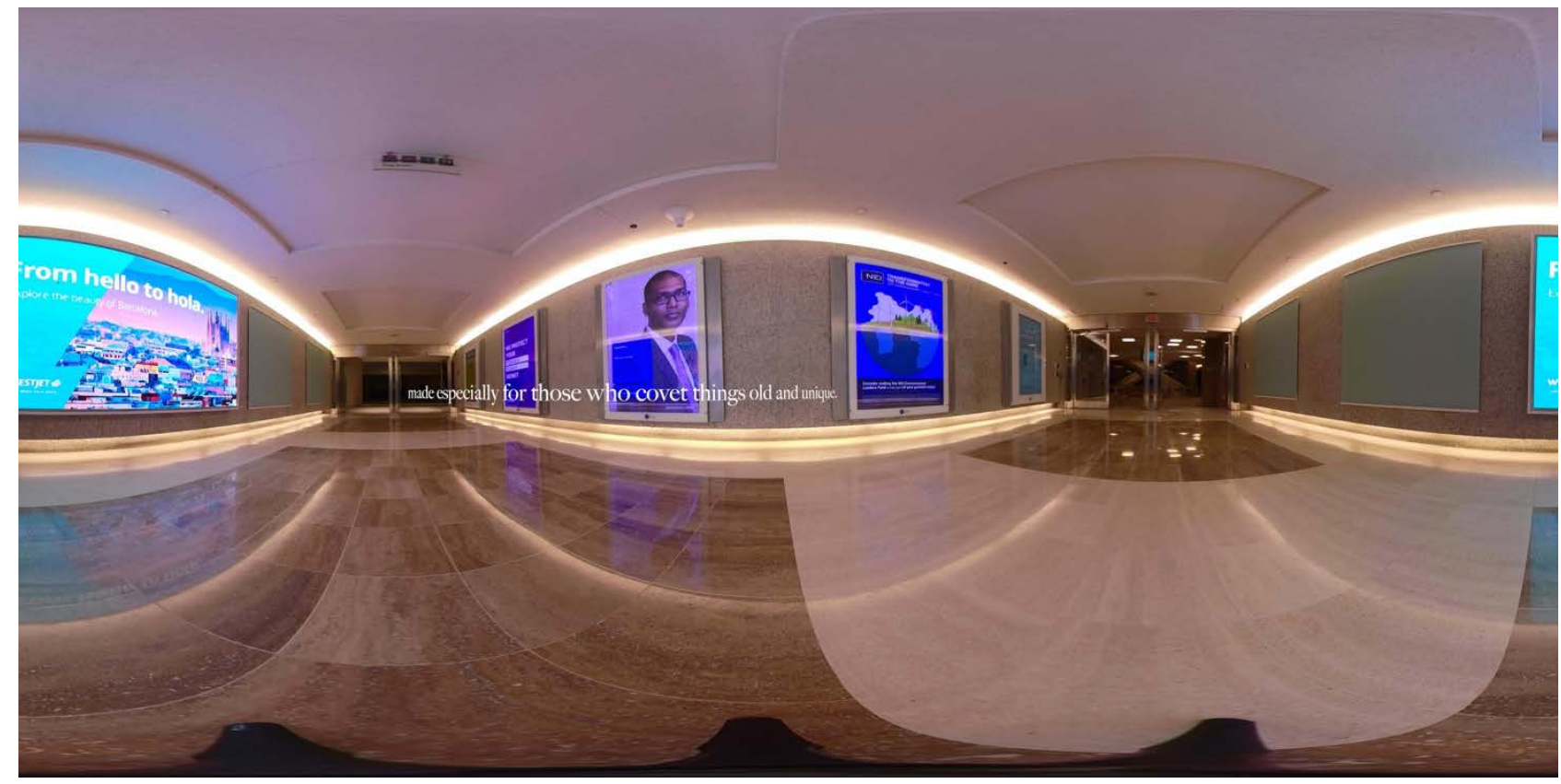

Figure 2. Ancient Thoughts and Electric Buildings: Production Still

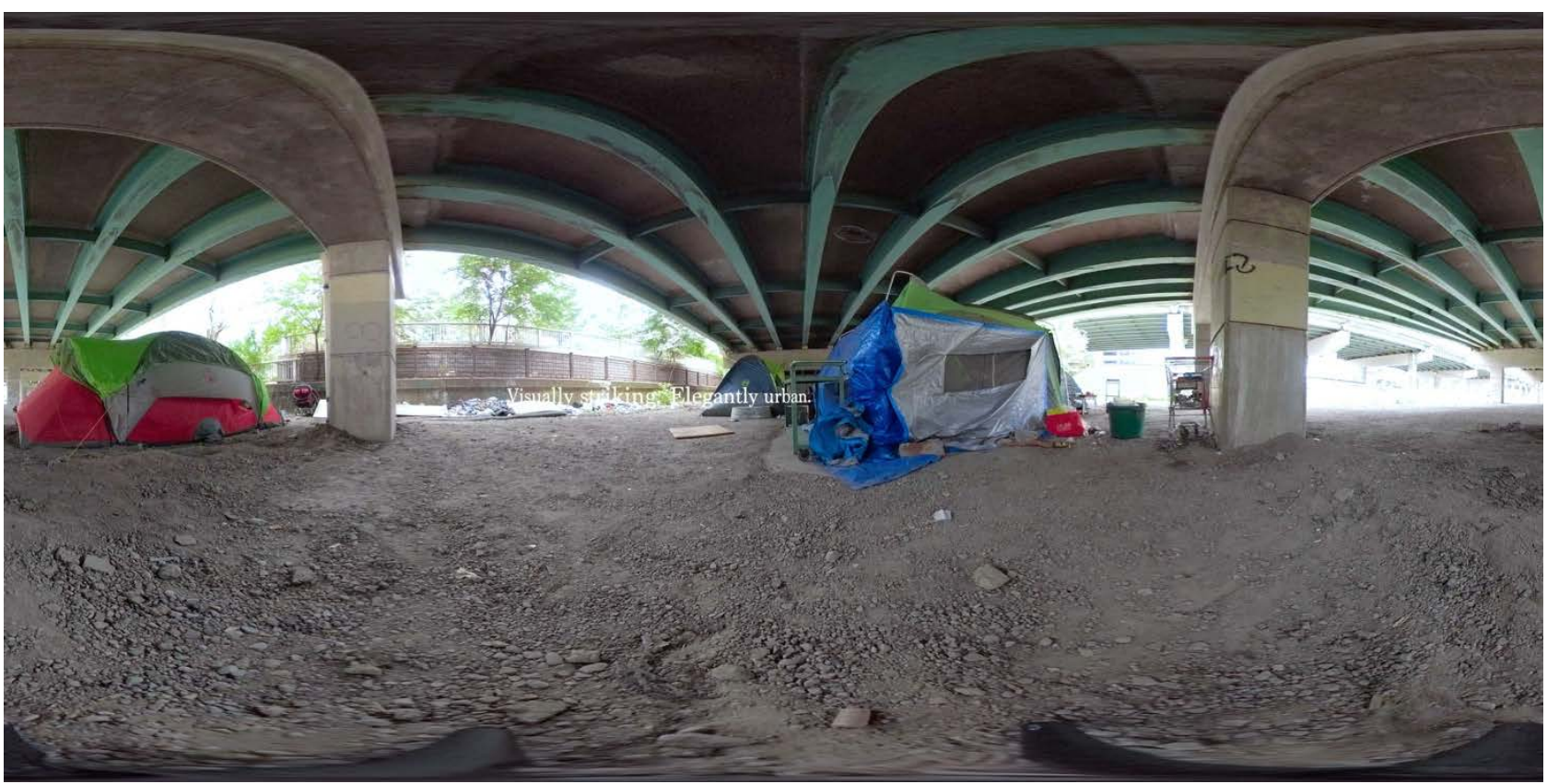

Figure 3. Ancient Thoughts and Electric Buildings: Production Still 